\title{
Silver glyconanoparticles functionalized with sugars of sweet sorghum syrup as an antimicrobial agent
}

\author{
C. Ganesh Kumar ${ }^{\mathrm{a}, *}$, Suman Kumar Mamidyala ${ }^{\mathrm{a}}$, M. Narsi Reddy ${ }^{\mathrm{a}}$, Belum V.S. Reddy ${ }^{\mathrm{b}}$ \\ a Chemical Biology Laboratory, Natural Products Chemistry Division, Indian Institute of Chemical Technology, Uppal Road, Hyderabad 500 607, India \\ b International Crops Research Institute for the Semi-Arid Tropics, Patancheru, Hyderabad 502 324, Andhra Pradesh, India
}

\section{A R T I C L E I N F O}

\section{Article history:}

Received 20 December 2011

Received in revised form 22 April 2012

Accepted 31 May 2012

Available online 8 June 2012

\section{Keywords:}

Silver glyconanoparticles

Sorghum syrup

Fructose

Glucose

Biomaterials

\begin{abstract}
A B S T R A C T
Bio-directed synthesis of metal nanoparticles is gaining importance due to their biocompatibility, low toxicity and eco-friendly nature. We used sweet sorghum syrup for a facile and cost-effective green synthesis of silver glyconanoparticles. Silver nanoparticles were formed due to reduction of silver ions when silver nitrate solution was treated with sorghum syrup solutions of different $\mathrm{pH}$ values. The nanoparticles were characterized by UV-vis, TEM (transmission electron microscopy), DLS (dynamic light scattering), EDAX (energy dispersive X-ray spectroscopy), FT-IR (fourier transform infrared spectroscopy) and XRD (X-ray diffraction spectroscopy). The silver glyconanoparticles exhibited a characteristic surface plasmon resonance around $385 \mathrm{~nm}$. At pH 8.5, the nanoparticles were mono-dispersed and spherical in shape with average particle size of $11.2 \mathrm{~nm}$. The XRD and SAED studies suggested that the nanoparticles were crystalline in nature. EDAX analysis showed the presence of elemental silver signal in the synthesized glyconanoparticles. FT-IR analysis revealed that glucose, fructose and sucrose present in sorghum syrup acted as capping ligands. Silver glyconanoparticles prepared at $\mathrm{pH} 8.5$ had a zeta potential of $-28.9 \mathrm{mV}$ and were anionic charged. They exhibited strong antimicrobial activity against Gram-positive, Gramnegative and different Candida species at MIC values ranging between 2 and $32 \mu \mathrm{g} \mathrm{ml}^{-1}$. This is first report on sweet sorghum syrup sugars-derived silver glyconanoparticles with antimicrobial property.
\end{abstract}

(c) 2012 Elsevier Ltd. All rights reserved.

\section{Introduction}

Nanotechnology deals with the synthesis, characterization and application of materials with nanoscale dimensions of atomic or molecular scale ranging from 1 to $100 \mathrm{~nm}$ [1]. Silver nanoparticles, due to their unique electronic and optical properties are dependent on their geometrical properties such as size and shape and find application in catalysis [2], photonics [3] and surface enhanced Raman scattering (SERS) [4]. The merging of "green chemistry" principles with nanotechnology and nanoscience has gained increased attention during the last decade [5]. Bio-directed synthesis of metal nanoparticles involves the use of reducing agents of biological origin; it is gaining importance due to their biocompatibility, low toxicity and eco-friendly nature [6]. Such nanoparticles find application as optical receptors, as catalysts in chemical reactions and as antibacterial agents [7], in biolabeling and spectral coating for solar energy absorption [8], and in bioremediation [9]. The synthesis of silver nanoparticles involving microorganisms such as bacteria, yeast, fungi, and actinomycetes $[10,11]$ have been reported; in addition many natural products like vitamin E [12],

\footnotetext{
* Corresponding author. Tel.: +91 40 27193105; fax: +91 4027193189.

E-mail addresses: cgkumar@iict.res.in, cgkumar1@rediffmail.com (C.G. Kumar).
}

plant extracts [13], honey [14], etc. have been used successfully for the preparation of silver nanoparticles. The formation of silver nanoparticles in microorganisms occurs either intracellularly [15] or extracellularly [16].

Sweet sorghum [Sorghum bicolor (L.) Moench] is a high sugaryielding crop cultivated worldwide under diverse agro-climatic conditions. Sweet sorghum stalks accumulate high levels of sugars like sucrose, glucose and fructose in the juice $[17,18]$. This property is advantageous as the sugars in honey were recently demonstrated for the synthesis of silver nanoparticles [14]. Nanoparticles capped with sugars as ligands are termed as glyconanoparticles. Recent studies focused on the synthesis of gold and silver glyconanoparticles that are functionalized with carbohydrates like glucose [19], lactose [20], Le ${ }^{y}$ tetrasaccharide [21], starch [5,22,23], and rhamnolipid [24]. These carbohydrates contain many hydroxyl and carbonyl groups which confer the glyconanoparticles with unique $\mathrm{H}$-bonding capabilities for building smart nanomaterials, and find biomedical applications as probes of carbohydrate-carbohydrate interactions and carbohydrate-protein interactions, anti-adhesive therapy, biolabels, etc. $[25,26]$. In continuation to our earlier study on the preparation of gold glyconanoparticles using sweet sorghum syrup [27], and the importance of glyconanoparticles from a biotechnological and biomedical perspective, we developed a simple and rapid green synthetic approach for the preparation of silver 
glyconanoparticles functionalized with sugars of sweet sorghum syrup and the application of these silver glyconanoparticles as an antimicrobial agent. The advantage of using sweet sorghum syrup is that it is a low-cost and renewable biomaterial with sugars, minerals, vitamins and proteins in which sugars acting as reducing and capping ligands during the formation of silver glyconanoparticles without the requirement of additional chemical reagents.

\section{Materials and methods}

\subsection{Materials}

Sweet sorghum syrup from cultivar CSH 22SS was obtained from the decentralized sweet sorghum crushing-cum-syrup making unit of the experimental farms of International Crops Research Institute for the Semi-Arid Tropics (ICRISAT) located at Ibrahimabad village, Medak district of Andhra Pradesh, India. The fresh syrup was collected in sterile sample bottles and then transported under cold ice-jacketed conditions to the laboratory and stored at $-20^{\circ} \mathrm{C}$ until used for further experimental analysis. Silver nitrate and $p$-iodonitrotetrazolium were purchased from Sigma-Aldrich and used as such without further purification. Other chemicals like glucose, fructose and sucrose were procured from Sisco Research Laboratories Pvt. Ltd., Mumbai, India. All aqueous solutions were prepared in distilled deionized water. The standard reference strains for antimicrobial activity were obtained from Microbial Type Culture Collection and Gene Bank (MTCC) of the Institute of Microbial Technology, Chandigarh, India.

\subsection{Composition analyses of sweet sorghum syrup}

Sugar concentration in terms of Brix (\%) was measured using a hand-held pocket refractometer (Model PAL, Atago Co. Ltd., Tokyo, Japan). Between two different sample readings, the refractometer was cleaned with distilled water and dried with a paper napkin. Sugar profiling to determine the relative percentages of hexose sugars like glucose, fructose and sucrose present in the sweet sorghum syrup of CSH 22SS cultivar were analyzed on a HPLC system (Shimadzu, Kyoto, Japan) equipped with a LichroCART 250-4,6 Lichrospher $100 \mathrm{NH}_{2}$ (5 $\mu \mathrm{m}$, Merck KGaA, Darmstadt, Germany). The detection of the separated sugars was carried out with a refractive index detector (Model RID-10A, Shimadzu, Kyoto, Japan) using a mobile phase of acetonitrile-water $(78: 22, \mathrm{v} / \mathrm{v})$ at a flow rate of $2.0 \mathrm{ml} \mathrm{min}^{-1}$ under isocratic mode and the column temperature was maintained at $40^{\circ} \mathrm{C}$. All solvents for mobile phase optimization were degassed before use. Standard stock solution $\left(1000 \mu \mathrm{g} \mathrm{ml}^{-1}\right)$ of different sugars was prepared in Milli-Q distilled water as a diluent for calibrating the HPLC system and a standard calibration was prepared for checking the reproducibility of the chromatograms. Different parameters like retention time, component concentration, peak area of each component were used for calculating the content of respective sugars. The juice sample analysis was done by manual injection of $20 \mu \mathrm{l}$ of prefiltered sample. The data acquisition and analysis was carried out using LC solutions software (version 1.24 SP2) (Shimadzu, Kyoto, Japan). The concentration of each sugar in the juice was determined using peak area from the chromatograms and expressed in terms of percentage of total sugars as described by Kumar et al. [28]. The stability of the sweet sorghum syrup was measured periodically every 15 days for its relative percentages of hexose sugars and our studies have indicated that the syrup maintained its sugar content for more than 6 months (data not shown). Atomic absorption spectrophotometer (AAnalyst 300, Perkin-Elmer, Norwalk, USA) was employed for the estimation of relative percentages of calcium (Ca), iron ( $\mathrm{Fe})$, potassium $(\mathrm{K})$ and silicon $(\mathrm{Si})$; while proteins present in sorghum syrup were estimated by Bradford assay [29].

\subsection{Preparation of silver glyconanoparticles}

Diluted sweet sorghum syrup solution was prepared by dissolving $10 \mathrm{~g}$ of sorghum syrup (of $60^{\circ}$ Brix) in $150 \mathrm{ml}$ of deionized water and used in further experiments on nanoparticle synthesis. Diluted sorghum syrup solution was adjusted to different $\mathrm{pH}$ values $(\mathrm{pH}$ $7.0,7.5,8.0,8.5$ and 9.0), and $1 \mathrm{ml}$ solution of individual pHs of the diluted sorghum syrup were mixed separately with $1 \mathrm{ml}$ solution of aqueous silver nitrate ( $1 \mathrm{mM})$ and the final volume was made up to $10 \mathrm{ml}$ by adding appropriate volume of deionized water.

\subsection{Characterization of silver glyconanoparticles}

UV-vis absorption spectra of silver glyconanoparticles in reaction mixtures were monitored on a Jasco V670 UV-vis double beam spectrophotometer [Jasco (UK) Ltd., Essex, UK], using a 1-cm path length quartz cell at room temperature. Morphological studies of silver glyconanoparticle formation were examined on a transmission electron microscope (TEM). The samples for TEM analysis were prepared by placing a drop of the suspension of reaction mixture containing silver glyconanoparticles on a Formvar-covered carboncoated copper grid and dried at room temperature overnight prior to the measurement. TEM images were recorded on a Philips Technai-FE 12 TEM instrument operating at $120 \mathrm{kV}$ accelerating voltage. The image acquisition and analysis was done using Soft Imaging software.

After the synthesis of silver glyconanoparticles, they were centrifuged at $12,000 \mathrm{rpm}$ for $10 \mathrm{~min}$ and the obtained pellet was washed three times with deionized water and then the nanoparticles were dried to obtain a powder which was further subjected to FT-IR, EDAX and XRD analyses. The FT-IR spectrum of the silver glyconanoparticles as $\mathrm{KBr}$ pellets was measured on a Thermo-Nicolet Nexus 670 spectrophotometer at $4 \mathrm{~cm} \mathrm{~s}^{-1}$ resolution in wave number region of $400-4000 \mathrm{~cm}^{-1}$. The energy-dispersive X-ray (EDAX) spectroscopy was recorded with an EDAX detector (Oxford LINKISIS 300) equipped on a scanning electron microscope (SEM, Hitachi $\mathrm{S}-520$ ) operated at $10 \mathrm{kV}$ accelerating voltage. The $\mathrm{X}$-ray diffraction (XRD) pattern of silver glyconanoparticles was recorded employing an MAXima_X XRD-7000 (Shimadzu, Japan) X-ray diffractometer operated at a voltage of $40 \mathrm{kV}$ and current of $30 \mathrm{~mA}$ using $\mathrm{CuK}_{\alpha}$ radiation in the scan range, $2 \theta=10-80^{\circ}$.

The powdered silver glyconanoparticles of different $\mathrm{pH}$ values were re-dispersed in deionized water by ultrasonication and subjected to dynamic light scattering (DLS) measurements on a Zetasizer Nano ZS (Malvern Instruments Ltd., Worcestershire, UK) instrument equipped with a He-Ne laser operating at $632.8 \mathrm{~nm}$ and a scattering detector at $173^{\circ}$. The silver glyconanoparticle charge quantified as zeta potential was determined using the same instrument at $25^{\circ} \mathrm{C}$.

\subsection{Antimicrobial activity of silver glyconanoparticles}

The silver glyconanoparticles prepared at $\mathrm{pH} 8.5$ of diluted sorghum syrup were tested for antimicrobial activity by microtiter broth dilution method [30]. Different indicator strains used were Gram-positive bacteria such as Bacillus subtilis MTCC 121, Staphylococcus aureus MLS16 MTCC 2940, S. aureus MTCC 96, Micrococcus luteus MTCC 2470; Gram-negative bacteria such as Escherichia coli MTCC 739, Klebsiella planticola MTCC 530 and Pseudomonas aeruginosa MTCC 2453 and different yeast strains like Candida albicans MTCC 227, C. parapsilosis MTCC 1744 and C. krusei MTCC 3020. Muller-Hinton broth and potato dextrose broth were used as culture media for bacterial and Candida strains, 


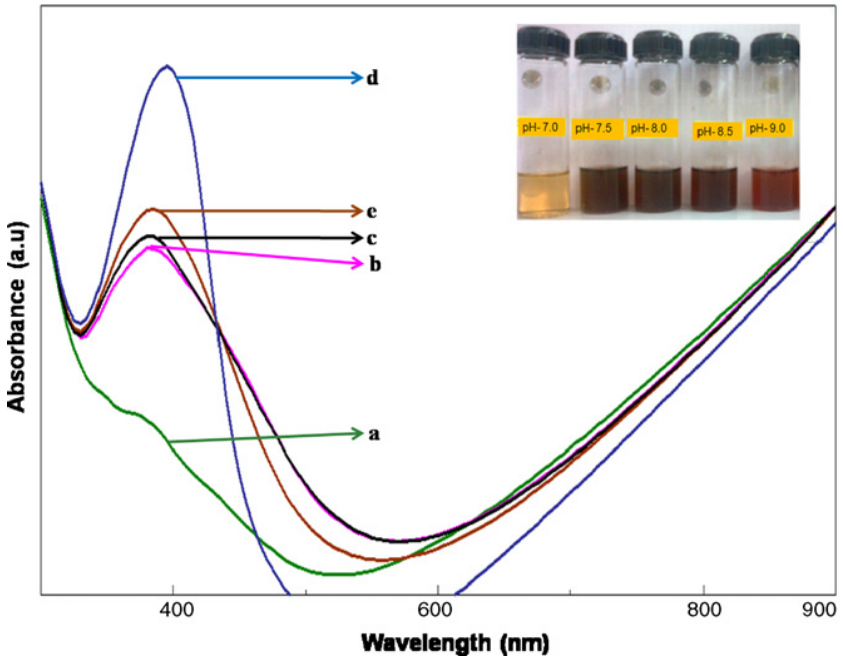

Fig. 1. UV-vis spectra of silver glyconanoparticles synthesized using sorghum syrup solutions of (a) pH 7.0, (b) pH 7.5, (c) pH 8.0, (d) pH 8.5, and (e) pH 9.0, represented by (a)-(e) curves. Inset shown on the right side: Reaction mixtures at different $\mathrm{pH}$ values.

respectively. About $10^{6} \mathrm{cfu} \mathrm{ml}^{-1}$ cells were inoculated and the final volume in each microtiter plate well was $0.1 \mathrm{ml}$. After incubation for $24 \mathrm{~h}$ at $35^{\circ} \mathrm{C}$ for bacterial strains and $28^{\circ} \mathrm{C}$ for Candida strains, $p$-iodonitrotetrazolium assay [31] was performed in which the microtiter plates were read at $450 \mathrm{~nm}$ using Infinite M200 (Tecan Group Ltd., Switzerland) spectrophotometer prior to and after incubation to determine the minimum inhibitory concentration (MIC) values. The MIC is defined as the lowest concentration of test compound which inhibited the $90 \%$ of the growth when compared with that of the growth control. Tetracycline and fluconazole were used as standard reference antibiotics against bacterial and Candida strains, respectively.

\section{Results and discussion}

\subsection{Composition analyses of sweet sorghum syrup}

The relative percentages of sugars estimated in sweet sorghum syrup of $\mathrm{CSH} 22 \mathrm{SS}$ cultivar were $20 \%, 14 \%$ and $65 \%$ for glucose, fructose and sucrose, respectively. Further, trace amounts of vitamins like $\mathrm{B}_{2}(1243 \mathrm{ppm})$ and $\mathrm{B}_{6}(29 \mathrm{ppm})$, elements like calcium (2455 ppm), iron (76.4 ppm), potassium (11,603 ppm), silicon $(7 \mathrm{ppm})$, and proteins $(0.49 \%)$ were also detected. The relative percentages of hexoses present in sorghum syrup remained unchanged over a period of 6 months, however after 6 months the concentrations of glucose and fructose increased while the sucrose concentration decreased (data not shown).

\subsection{Synthesis of silver glyconanoparticles}

The diluted sweet sorghum syrup solutions of different $\mathrm{pH}$ values reduced the silver ions immediately at room temperature resulting in the spontaneous formation of yellow color which evidenced the formation of silver glyconanoparticles. This could be attributed to the direct redox reaction between the biomolecules present in the sorghum syrup and silver nitrate, since there was no addition of any reducing agent in the reaction mixture. The bioreduction of silver ions was monitored by UV-vis spectroscopy and the extinction spectra of silver glyconanoparticles are shown in Fig. 1. The extinction spectra showed a typical surface plasmon resonance (SPR) band of spherical silver glyconanoparticles, whose origin could be due to the collective oscillations of the conductive electrons within the glyconanoparticles. The optical absorption spectrum of metal nanoparticles is dominated by the SPR resulting in a distinguished red or blue shift depending on the dielectric properties of the surrounding host matrix or the environment atmosphere, in addition to the particle size and shape [32]. Indeed, the optical behavior of silver glyconanoparticles was affected by surface functionalization and size, for example, a red shift in SPR was observed from $400 \mathrm{~nm}$ to $430 \mathrm{~nm}$ after functionalization of silver glyconanoparticles with glucosamine [33]. The broad plasmon resonance peak with very low intensity was centered at around $385 \mathrm{~nm}$ at $\mathrm{pH} 7$ and the intensity of SPR peak as well as sharpness increased gradually with an increase in the $\mathrm{pH}$ from 7.5 to 8.0. At pH 8.5 and 9.0, a further increase in the absorbance intensity was observed, however a shift in the position of SPR peak observed which was centered at $395 \mathrm{~nm}$. The absorbance intensity was found to be higher at $\mathrm{pH} 8.5$ when compared to other $\mathrm{pH}$ values suggesting that the conditions at $\mathrm{pH} 8.5$ favored the efficient reduction of $\mathrm{Ag}$ ions. It has been earlier reported that the optical properties of silver nanoparticles are influenced by their shape and size [34]. These results indicate that the obtained silver glyconanoparticles are spherical in shape as the SPR lie between 380 and $500 \mathrm{~nm}$ for spherical silver nanoparticles [35]. The optical behavior of silver glyconanoparticles (capped by sugars like glucose, maltose and lactose) prepared using classical reagents related to SPR lie between 380 and $430 \mathrm{~nm}$ and our results fit well in this regard [36].

\subsection{Morphological analysis of silver glyconanoparticles}

To gain a detailed understanding of $\mathrm{pH}$ influence on the size and shape of silver glyconanoparticles, we examined the surface morphology of the silver glyconanoparticles by transmission electron microscope (TEM). TEM micrographs shown in Fig. 2A-D demonstrate clearly the formation of silver glyconanoparticles synthesized using sorghum syrup solutions adjusted to different $\mathrm{pH}$ values. The TEM analysis of silver glyconanoparticles prepared with sorghum syrup solution of $\mathrm{pH} 7.0$ clearly revealed the formation of agglomerated nanoparticles of irregular shape (data not shown). The silver glyconanoparticles prepared at pH 7.5 (Fig. 2A) and 8.0 (Fig. 2B) were found to be non-agglomerated and predominantly were spherical in shape but few of them were irregular in shape. The average size also decreased as the $\mathrm{pH}$ increased from $\mathrm{pH} 7.5$ to 8.0 (see Table 1). The TEM micrographs of $\mathrm{pH} 8.5$ (Fig. 2C) revealed the formation of fairly spherical and mono-dispersed silver glyconanoparticles. The size distribution histogram constructed from the concerned TEM images is shown in Fig. 2E. Average size of nanoparticles computed from the histogram was found to be $11.2(\sigma= \pm 2.06 \mathrm{~nm})$ with a narrow size distribution. However, at a higher $\mathrm{pH}$ of 9.0, a slight aggregation behavior of nanoparticles was observed (Fig. 2D). It is therefore suggested that $\mathrm{pH} 8.5$ is optimal for obtaining well-dispersed silver glyconanoparticles due to minimized aggregation behavior. The results also clearly suggested that the average size gradually decreased (see Table 1) and the spherical nature of glyconanoparticles increased as the $\mathrm{pH}$ of the sorghum solution increased and at a higher $\mathrm{pH}$ of 8.5 , the control over the shape was well demonstrated. The $\mathrm{pH}$ value also indicates proton $\left(\mathrm{H}^{+}\right)$concentration and as the $\mathrm{pH}$ increases the proton concentration decreases. So at a higher $\mathrm{pH}$ of 8.5 , a decrease in the proton concentration was observed which favored the formation of well-dispersed silver glyconanoparticles.

Average particle size and size distribution (polydispersity index, PDI) of the nanoparticles synthesized at different $\mathrm{pH}$ values of sorghum syrup were also determined by DLS and results to this regard are indicated in Table 1 . The average size of nanoparticles gradually decreased as $\mathrm{pH}$ increased, coinciding with the TEM results, and lowest size was recorded at $\mathrm{pH} 8.5(78 \mathrm{~nm})$. However, 

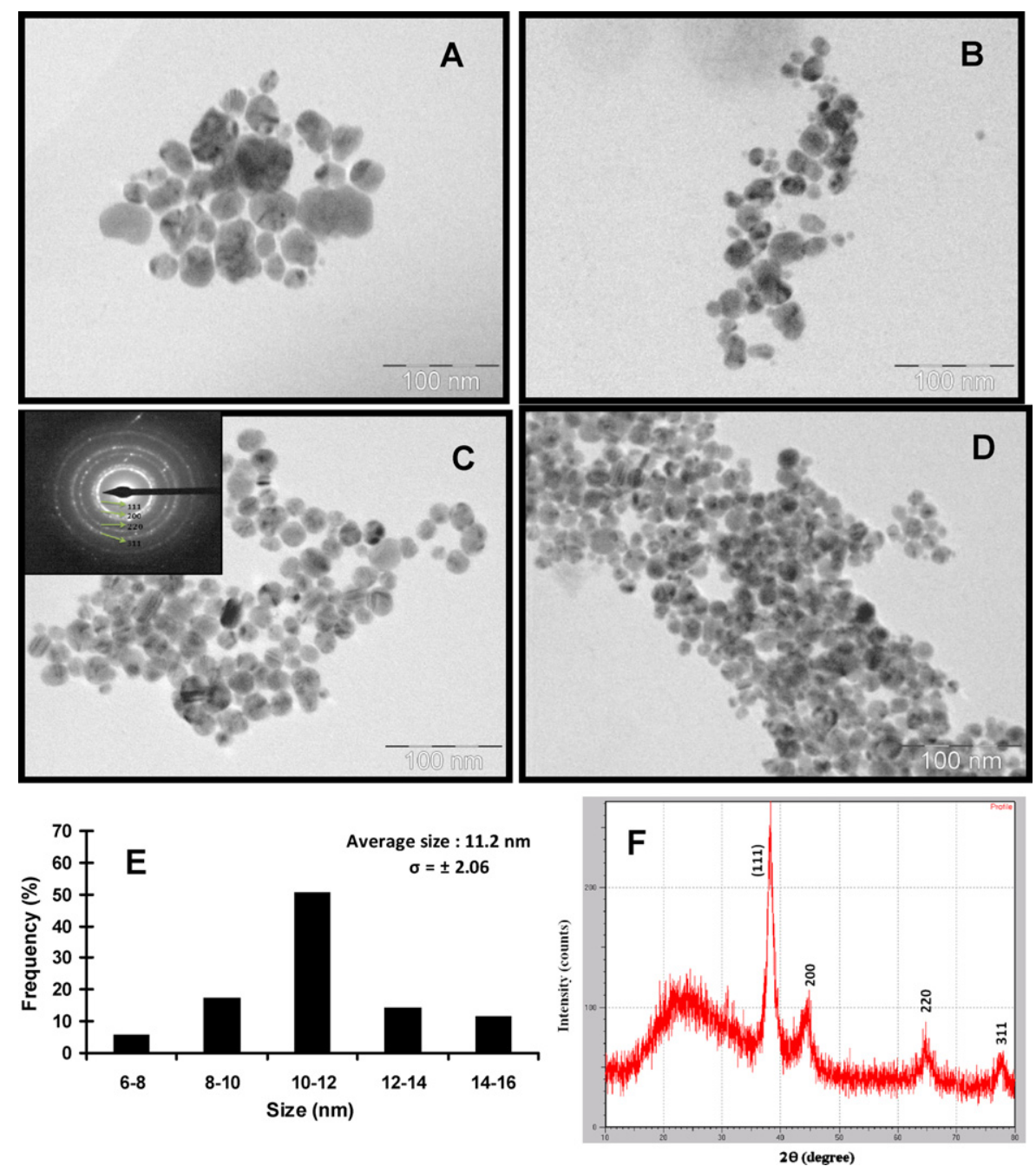

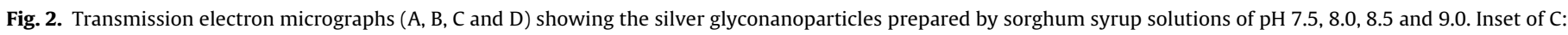

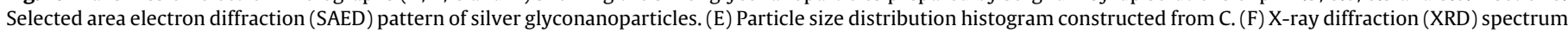
of silver glyconanoparticles exhibiting characteristic Bragg's diffraction peaks.

the hydrodynamic diameters of silver glyconanoparticles were found to be larger than the corresponding TEM size (Table 1), which could be due to the aggregation of glyconanoparticles (instability). This data could be supported by zeta potential values (Table 1 ) as none of them had a charge either above -30 or $+30 \mathrm{mV}$ which is generally required for stability of glyconanoparticles [37]. The polydispersity index of glyconanoparticles (Table 1 ) were found to be below 0.7 , except at $\mathrm{pH} 7$ (0.97), suggesting that the nanoparticles were mono-dispersed, except at $\mathrm{pH} 7$, which are poly-dispersed and these results matched with the TEM results. Polydispersity index is a parameter to define the particle size distribution of nanoparticles which have values ranging from 0.01 to 0.7 for monodispersed particles and above 0.7 for polydispersed particles [38].
The crystalline nature of silver glyconanoparticles was investigated from the typical selected area electron diffraction (SAED) pattern (Fig. 2C inset), which showed reflections corresponding to the (111), (200), (220) and (311) planes for the fcc structure of Ag crystal. The X-ray diffraction (XRD) spectrum analysis of silver glyconanoparticles synthesized using sweet sorghum syrup solution is shown in Fig. 2F, which revealed the distinct Bragg diffraction peaks at $2 \theta$ values of $38.1,44.4$ and 64.7 and 77.6 that were indexed as (1 11), (200), (220) and (311) facets of the face centered cubic (fcc) silver nanoparticle, which confirmed the observations of SAED pattern. These characteristic diffraction peaks for the silver glyconanoparticles clearly indicates the crystalline nature of the silver glyconanoparticles.

Table 1

Average size, size distribution and zeta potential of silver glyconanoparticles obtained at different pH values.

\begin{tabular}{|c|c|c|c|c|c|}
\hline \multirow[t]{2}{*}{ Parameters } & \multicolumn{5}{|l|}{$\mathrm{pH}$} \\
\hline & 7.0 & 7.5 & 8.0 & 8.5 & 9.0 \\
\hline Mean primary particle size (nm) (TEM) & $\mathrm{ND}^{\mathrm{a}}$ & $24 \pm 8.0$ & $15.6 \pm 5.5$ & $11.2 \pm 2.0$ & $11.6 \pm 3.5$ \\
\hline Hydrodynamic diameter (nm) (DLS) & 1325 & 418 & 268 & 78 & 111 \\
\hline Polydispersity index (PDI) & 0.97 & 0.32 & 0.56 & 0.42 & 0.41 \\
\hline Zeta potential $(\mathrm{mV})$ & -7.8 & -9.59 & -11.9 & -28.9 & -25 \\
\hline
\end{tabular}

\footnotetext{
${ }^{a}$ ND: not determined.
} 


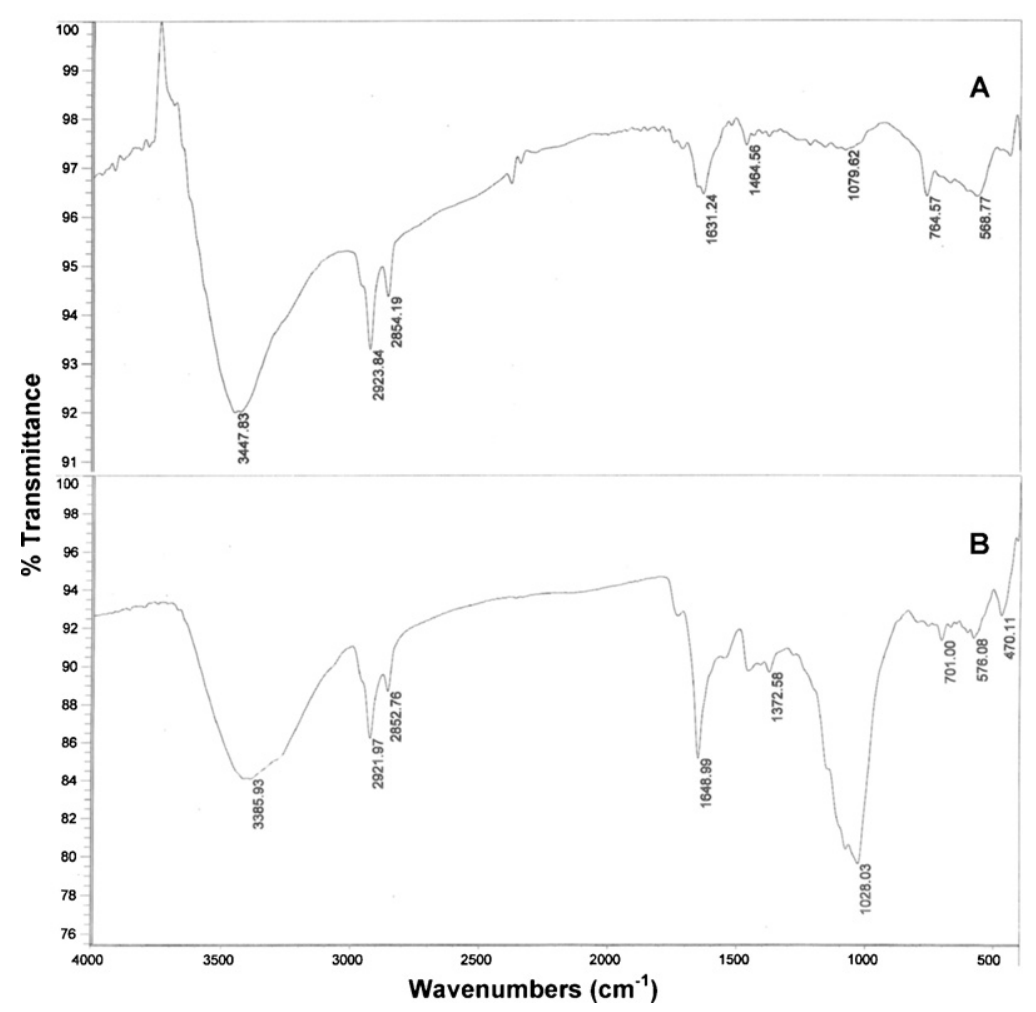

Fig. 3. FT-IR spectrum of (A) sorghum syrup solution, and (B) dried silver glyconanoparticles obtained at pH 8.5 .

\subsection{Molecules engaged in stabilization and reduction of silver glyconanoparticles}

Fourier transform-infrared (FT-IR) and energy dispersive Xray (EDAX) studies were carried out to evaluate the possible biomolecules responsible for capping and stabilization of silver glyconanoparticles synthesized by sorghum syrup solution. The FT-IR spectrum of silver glyconanoparticles obtained at pH 8.5 (Fig. 3B) showed the presence of bands at wavenumbers of 3385, 2921, 2852, 1648, 1372 and $1028 \mathrm{~cm}^{-1}$. The bands observed at 3385 and $1648 \mathrm{~cm}^{-1}$ are due to hydroxyl and carbonyl stretch vibrations in the sugars (glucose, fructose and/or sucrose) present in the sorghum syrup, respectively. The bands at 2921 and $2852 \mathrm{~cm}^{-1}$ are the result of the stretching vibrations of $\mathrm{C}-\mathrm{H}$ groups of sugars. A combination band of $\mathrm{OCH}$ and $\mathrm{COH}$ deformation was observed at $1372 \mathrm{~cm}^{-1}$. A band of $\mathrm{C}-\mathrm{O}$ and $\mathrm{C}-\mathrm{C}$ stretching vibrations in sugars was observed at $1028 \mathrm{~cm}^{-1}$. Similarly, a combination band of $\mathrm{CCO}$ and $\mathrm{CCH}$ was attributed to $701 \mathrm{~cm}^{-1}$. The region from 1500 to $600 \mathrm{~cm}^{-1}$ corresponded to the $\mathrm{C}-\mathrm{O}$ and $\mathrm{C}-\mathrm{C}$ group vibration modes and carbohydrates generally shows their characteristic bands [39]. These bands were found to be blue shifted except the carbonyl stretch (red shift) when compared to FT-IR spectrum of sorghum syrup solution (Fig. 3A) and this could be due to the coordination bonds between silver glyconanoparticles and functional groups of sugar molecules (capping ligands) of sorghum syrup solution.

The EDAX spectrum (Fig. 4) recorded for the synthesized silver glyconanoparticles with a strong absorption signal near at $3 \mathrm{keV}$, clearly indicating the presence of the silver element in the synthesized silver glyconanoparticles. The EDAX spectrum also suggests the presence of $C$ and $O$ elemental peaks which appeared due to the scattering caused by the biomolecules that are bound to the surface of silver glyconanoparticles. The Ca and Si elemental signals observed in the EDAX spectrum may arise from the sorghum syrup and/or likely to be caused by X-ray emission from the glass substrate used in the EDAX analysis as reported earlier by Nangia et al. [40], and the absorption peak corresponding to S may arise from proteins and/or free sulfur present in sorghum syrup.

The FT-IR and EDAX spectroscopic studies strongly suggest that the silver nanoparticles are functionalized by the sugars (like glucose, fructose and/or sucrose) present in the syrup and are stabilized by these biomolecules. The zeta potential indicates the overall charge that a nanoparticle acquires in a particular medium and negative zeta potential values were recorded for all nanoparticles (Table 1) suggesting an anionic charge on the nanoparticle surface which may be due to sugar moieties bound to the surface of synthesized silver glyconanoparticles and the result supports the FT-IR and EDAX analysis.

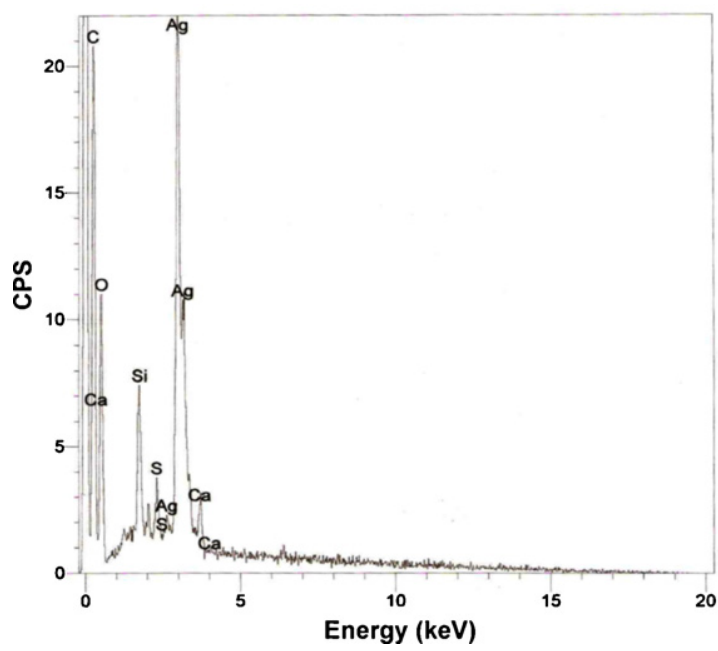

Fig. 4. Energy dispersive X-ray (EDAX) spectrum of silver glyconanoparticles obtained at $\mathrm{pH} 8.5$. 


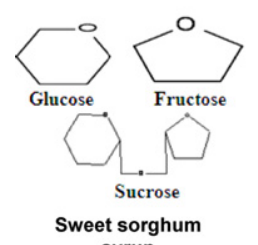

syrup

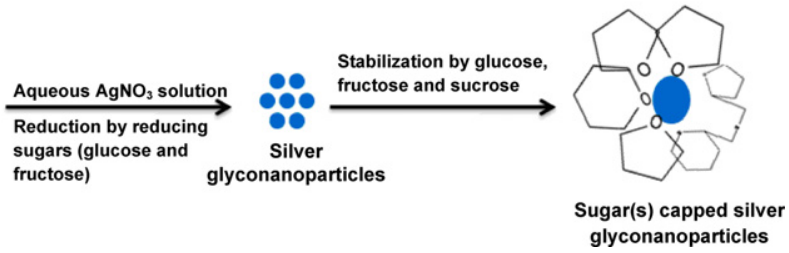

Fig. 5. Schematic representation of the proposed mechanism for formation and stabilization of silver glyconanoparticles.

The possible sugars responsible for the reduction of silver ions are the reducing sugars like glucose and fructose; while sucrose contributes to $65 \%$ in the total sorghum syrup which may have major involvement in the stabilization along with these reducing sugars. An earlier study indicated that commonly available simple sugars like glucose and fructose assisted in the synthesis of stable silver nanoparticles by a wet chemical synthesis method and fructose was identified as a possible sugar for reduction process [41]. In the present study, the sugars present in sorghum syrup performed dual functions which included the reduction as well as capping of the nanoparticles. After the reduction of $\mathrm{Ag}^{+}$to silver atoms by the reducing sugars; the formation of silver nanoparticles occurred by the condensation and particle growth processes [42]. Even though the sugars formed a capping layer around the nanoparticles they were incapable of preventing the agglomeration when nanoparticles were small due to predomination of attraction forces among the nanoparticles over the repulsive forces [42]. Thus as the size increased via condensation reactions; however, at a particular size the growth would be ceased by this mechanism as nanoparticles experience enough repulsive forces (due to negative charge of capping ligands) which prevented the aggregation of nanoparticles.

The mechanism (Fig. 5) on which the silver glyconanoparticle formation and stabilization occurred in the present study is based on the macromolecular crowding phenomenon, and in the present context, the sugars present in the sweet sorghum syrup occupy $\sim 15 \%$ of the total aqueous volume, which impose a physical constraint that secludes the silver nanoparticles from each other, thus preventing their aggregation. This macromolecular crowding phenomenon in cell biology is well demonstrated to affect the dynamics of many molecular and physical processes [43].

Some of the glyconanoparticles functionalized with lactose [44], polysaccharide [45] and glucosamine [33] were prepared using classical two-phase chemical synthesis which involved the use of water as an aqueous phase and solvents like toluene, dichloromethane, ethylene glycol, etc. as an organic phase. Besides these reagents, sodium citrate or $\mathrm{NaBH}_{4}$ were used as reducing agents, along with synthetic surfactants which acted as phasetransfer reagents in these preparations $[20,21,25,33,46]$, which are not environmentally safe and are toxic to the health. Moreover, these classical methods involve either one-step or multi-step approaches for the synthesis of silver nanoparticles which do not yield desired results when applied for the production of sugar capped silver glyconanoparticles [47]. Very few reports exist on preparation of metal nanoparticles prepared with sugar-based natural resources like honey [14] and sugar beet pulp [48]. In case of honey assisted-silver nanoparticle synthesis, fructose and proteins acted as reducing and capping agents, respectively. While, sugar beet pulp acted as a reducing agent in case of sugar beet pulp-based nanoparticles. On the other hand, sweet sorghum syrup has several advantages such as it is an easily available, low-cost, renewable biomaterial and the sugar ligands possess both reducing and capping properties, while other components like minerals, vitamins and proteins may also assist (enabling a healthy environment) in the formation of silver glyconanoparticles. One more advantage is that it involves a one-step generation of silver glyconanoparticles and is also considered to be advantageous over commercial sweeteners like high fructose corn syrups, which contain only glucose and fructose for the production of silver glyconanoparticles [49]. Considering these advantages, it was explored in a facile, safe, economical and green strategy to prepare glyconanoparticles in an aqueous milieu without the addition of any solvents, reducing and phase-transfer chemical reagents.

\subsection{Antimicrobial activity of silver glyconanoparticles}

The antimicrobial activity, indicative of biological behavior, of silver glyconanoparticles prepared at $\mathrm{pH} 8.5$ was evaluated against various pathogenic reference strains including Gram-positive, Gram-negative bacteria and different Candida species and results in this regard are displayed in Table 2 . The silver glyconanoparticles exhibited lowest minimum inhibitory concentration (MIC) against S. aureus MTCC 96 at $2 \mu \mathrm{g} \mathrm{ml}^{-1}$ and against E. coli MTCC 739, B. subtilis MTCC 121 and S. aureus MLS 16 MTCC 2940 at $4 \mu \mathrm{g} \mathrm{ml}^{-1}$. They also exhibited good antifungal activity against Candida sp suggesting the broad spectrum nature of antimicrobial activity. This antimicrobial behavior is due to the penetration of silver glyconanoparticles into the bacteria resulting in the damage of cell membrane and release of cell contents as suggested earlier [36]. Another possibility suggested was the release of silver ions from the glyconanoparticles, which may contribute to the bactericidal properties of silver glyconanoparticles [50].

In the recent years, the research on silver nanoparticles has regained importance in view of the increase of bacterial resistance to antibiotics due to their extensive overuse [51]. Therefore, silver nanoparticles and other silver-based compounds or preparations containing ionic silver $\left(\mathrm{Ag}^{+}\right)[52,53]$ or elemental silver $\left(\mathrm{Ag}^{0}\right)$ $[54,55]$ have been synthesized which exhibit antimicrobial activity. It was well established earlier that the antimicrobial activity of silver nanoparticles depends on their size; smaller the particle size, greater the activity [7]. This can be explained by the fact that smaller particles having the larger surface area available for interaction will give more bactericidal effect than larger particles. Since, the dimensions of silver glyconanoparticles obtained in this study are influenced by the $\mathrm{pH}$ of the sorghum syrup solution as revealed by TEM studies and antimicrobial activity is dependent on the dimensions of silver glyconanoparticles indicating the indirect effect of $\mathrm{pH}$ of the sorghum syrup solution on antimicrobial activity. The earlier research findings by Panacek et al. [36] also revealed that the silver glyconanoparticles with an average size of $50 \mathrm{~nm}$ (measured by DLS) showed MIC values ranging between 6.75 and $54 \mu \mathrm{g} \mathrm{ml}^{-1}$ against different bacterial pathogenic strains. In another study, glucosamine-functionalized silver glyconanoparticles with an average size of $35 \mathrm{~nm}$ (measured by TEM) exhibited antimicrobial activity with MIC values ranging between 8 and $512 \mu \mathrm{g} \mathrm{ml}^{-1}$ against various Gram-positive and Gram-negative bacteria [33]. Further, in our earlier study [56] we observed that silver nanoparticles prepared with $P$. aeruginosa culture supernatant showed an average particle size of $13 \mathrm{~nm}$ and exhibited MIC values ranging between 4 and $32 \mu \mathrm{g} \mathrm{ml}^{-1}$ against 
Table 2

Antimicrobial activity of silver glyconanoparticles against different bacterial and Candida strains.

\begin{tabular}{|c|c|c|c|}
\hline \multirow[t]{2}{*}{ Indicator strains ${ }^{\mathrm{a}}$} & \multicolumn{3}{|c|}{ Minimum inhibitory concentration (MIC, $\mu \mathrm{g} \mathrm{ml}^{-1}$ ) } \\
\hline & $\begin{array}{l}\text { Silver } \\
\text { glyconanoparticles }\end{array}$ & Tetracycline $^{\mathrm{b}}$ & Fluconazole $^{\mathrm{c}}$ \\
\hline \multicolumn{4}{|l|}{ Gram-positive bacteria } \\
\hline Bacillus subtilis MTCC 121 & 4 & 2 & - \\
\hline Staphylococcus aureus MLS16 MTCC 2940 & 4 & 4 & - \\
\hline Staphylococcus aureus MTCC 96 & 2 & 1 & - \\
\hline Micrococcus luteus MTCC 2470 & 8 & 1 & - \\
\hline \multicolumn{4}{|l|}{ Gram-negative bacteria } \\
\hline Escherichia coli MTCC 739 & 4 & 0.5 & - \\
\hline Pseudomonas aeruginosa MTCC 2453 & 8 & 8 & - \\
\hline Klebsiella planticola MTCC 530 & 16 & 1 & - \\
\hline \multicolumn{4}{|l|}{ Yeasts } \\
\hline Candida albicans MTCC 227 & 16 & - & 32 \\
\hline Candida parapsilosis MTCC 1744 & 16 & - & 16 \\
\hline Candida krusei MTCC 3020 & 32 & - & 128 \\
\hline
\end{tabular}

a Experiments were repeated three times and average values are shown.

b Tetracycline (standard antibacterial agent).

c Fluconazole (standard antifungal agent).

different pathogenic bacterial and Candida strains. Whereas, in the present study, the synthesized silver glyconanoparticles exhibited MIC values ranging between 2 and $16 \mu \mathrm{g} \mathrm{ml}^{-1}$ and were comparable to standard reference antibiotic (tetracycline), suggesting their potential antibacterial property when compared to silver glyconanoparticles prepared using classical methods as mentioned earlier. Further, the silver glyconanoparticles were found to have effective antifungal activity against different Candida spp., which is more or less equal to fluconazole, a standard antifungal agent, indicating their potential as an antifungal agent in the treatment of fungal infections. It was earlier demonstrated that the mode of antifungal action of silver glyconanoparticles on C. albicans is that the release of silver ions from the glyconanoparticles may contribute to the disruption of the yeast cell membrane structure and inhibit the normal budding process due to the destruction of the membrane integrity [50].

\section{Conclusion}

In this study, a facile, rapid and green protocol for the synthesis of silver glyconanoparticles at room temperature was demonstrated for the first time, which is based on the reduction of silver nitrate by the sugars of sweet sorghum syrup, serving both as reducing and capping agent in which sucrose plays a major role in stabilization. In the whole process, there is no use of high temperatures, toxic reagents, surfactants and/or organic solvents, so the present reported method of nanoparticle synthesis is eco-friendly and pollutant-free.

\section{Acknowledgments}

The authors acknowledge the financial assistance provided in the form of a Senior Research Fellowship by the Council of Scientific and Industrial Research (CSIR), New Delhi, India to Mr. S.K. Mamidyala. The authors are thankful to Dr. B. Sreedhar for extending the help in TEM studies. The authors are also grateful to Prof. V. Lakshmipati for his valuable suggestions and comments during the preparation of the manuscript. The authors are also grateful to the anonymous reviewers for their positive criticism and constructive comments.

\section{References}

[1] Thrall JH. Nanotechnology and medicine. Radiology 2004;230:315-8.

[2] Jiang Z-J, Liu C-Y, Sun L-W. Catalytic properties of silver nanoparticles supported on silica spheres. J Phys Chem B 2005;109:1730-5.
[3] Dadosh T, Sperling J, Bryan GW, Breslow R, Shegai T, Dyshel M, et al. Plasmonic control of the shape of the Raman spectrum of a single molecule in a silver nanoparticle dimer. ACS Nano 2009;3:1988-94.

[4] Wei D, Qian W, Wu D, Xia Y, Liu X. Synthesis, properties, and surface enhanced Raman scattering of gold and silver nanoparticles in chitosan matrix. J Nanosci Nanotechnol 2009;9:2566-73.

[5] Raveendran P, Fu J, Wallen SL. Completely green synthesis and stabilization of metal nanoparticle. J Am Chem Soc 2003;125:13940-1.

[6] Anastas PT, Warner JC. Green chemistry: theory and practice. New York: Oxford University Press, Inc.; 1998.

[7] Baker C, Pradhan A, Pakstis L, Pochan DJ, Shah SI. Synthesis and antibacterial properties of silver nanoparticles. J Nanosci Nanotechnol 2005;5: 244-9.

[8] Klaus T, Joerger R, Olsson E, Granqvist CG. Bacteria as workers in the living factory: metal-accumulating bacteria and their potential for materials science. Trends Biotechnol 2001;19:15-20.

[9] Duran N, Marcato PD, De S, Gabriel IH, Alves OL, Esposito E. Antibacterial effect of silver nanoparticles produced by fungal process on textile fabrics and their effluent treatment. J Biomed Nanotechnol 2007;3:203-8.

[10] Mandal D, Bolander ME, Mukhopadhyay D, Sarkar G, Mukherjee P. The use of microorganisms for the formation of metal nanoparticles and their application. Appl Microbiol Biotechnol 2006;69:485-92.

[11] Gericke M, Pinches A. Biological synthesis of metal nanoparticles. Hydrometallurgy 2006;83:132-40.

[12] Zhang L, Shen YH, Xie AJ, Li SK, Jin BK, Zhang QF. One-step synthesis of monodisperse silver nanoparticles beneath vitamin E Langmuir monolayers. J Phys Chem B 2006;110:6615-20.

[13] Kumar V, Yadav SK. Plant mediated synthesis of silver and gold nanoparticles and their applications. J Chem Technol Biotechnol 2009;84:151-7.

[14] Philip D. Honey mediated green synthesis of silver nanoparticles. Spectrochim Acta Part A 2010;75:1078-81.

[15] Mukherjee P, Ahmad A, Mandal D, Senapati S, Sainkar SR, Khan MI, et al. Fungus mediated synthesis of silver nanoparticles and their immobilization in the mycelial matrix a novel biological approach to nanoparticle synthesis. Nano Lett 2001;1:515-9.

[16] Kumar SA, Abyaneh MK, Gosavi SW, Kulkarni SK, Pasricha R, Ahmad A, et al. Nitrate reductase-mediated synthesis of silver nanoparticles from $\mathrm{AgNO}_{3}$. Biotechnol Lett 2007;29:439-45.

[17] Reddy BVS, Ramesh S, Sanjana Reddy P, Ramaiah B, Salimath PM, Rajasekhar K. Sweet sorghum-A potential alternate raw material for bio-ethanol and bioenergy. Int Sorghum Millets Newslett 2005;46:79-86.

[18] Reddy BVS, Ramesh S, Ashok Kumar A, Wani SP, Ortiz R, Ceballos H, et al. Biofuel crops research for energy security and rural development in developing countries. Bioenergy Res 2008;1:248-58.

[19] Barrientos AG, De la Fuente JM, Rojas TC, Fernández A, Penadés S Gold glyconanoparticles: synthetic polyvalent ligands mimicking glycocalyxlike surfaces as tools for glycobiological studies. Chem Eur J 2003;9: 1909-21.

[20] De la Fuente JM, Barrientos AG, Rojas TC, Rojo J, Cañada J, Fernández A, et al. Gold glyconanoparticles as water-soluble polyvalent models to study carbohydrate interactions. Angew Chem Int Ed 2001;40:2257-61.

[21] De Paz JL, Ojeda R, Barrientos AG, Penadés S, Martín-Lomas M. Synthesis of a Lex neoglycoconjugate and $\mathrm{Le}^{\mathrm{y}}$-functionalized gold glyconanoparticles. Tetrahedron Asymmetry 2005;16:149-58.

[22] Raveendran P, Fu J, Wallen SL. A simple and green method for the synthesis of $\mathrm{Au}, \mathrm{Ag}$, and Au-Ag alloy nanoparticles. Green Chem 2006;8:34-8.

[23] Vigneshwaran N, Nachane RP, Balasubramanya RH, Varadarajan PV. A nove one-pot 'green' synthesis of stable silver nanoparticles using soluble starch. Carbohydr Res 2006;341:2012-8. 
[24] Kumar CG, Mamidyala SK, Das B, Sridhar B, Sarala Devi G, Karuna MSL. Synthesis of biosurfactant-based silver nanoparticles with purified rhamnolipids isolated from Pseudomonas aeruginosa BS-161R. J Microbiol Biotechnol 2010;20:1061-8.

[25] De la Fuente JM, Penadés S. Glyco-quantum dots: a new luminescent system with multivalent carbohydrate display. Tetrahedron Asymmetry 2005;16:387-91.

[26] De la Fuente JM, Penadés S. Glyconanoparticles: types, synthesis and applications in glycoscience, biomedicine and material science. Biochim Biophys Acta 2006;1760:636-51.

[27] Kumar CG, Mamidyala SK, Sreedhar B, Reddy BVS. Synthesis and characterization of gold glyconanoparticles functionalized with sugars of sweet sorghum syrup. Biotechnol Prog 2011;27:1455-63.

[28] Kumar CG, Fatima A, Srinivasa Rao P, Reddy BVS, Rathore A, Nageswar Rao R, et al. Characterization of improved sweet sorghum genotypes for biochemical parameters, sugar yield and its attributes at different phenological stages. Sugar Tech 2010;12:322-8.

[29] Bradford MM. A rapid and sensitive method for the quantitation of microgram quantities of protein utilizing the principle of protein-dye binding. Anal Biochem 1976;72:248-54.

[30] Satyajit DS, Nahar L, Kumarasamy Y. Microtitre plate-based antibacterial assay incorporating resazurin as an indicator of cell growth, and its application in the in vitro antibacterial screening of phytochemicals. Methods 2007;42:321-4.

[31] Eloff JN. A sensitive and quick microplate method to determine the minimal inhibitory concentration of plant extracts for bacteria. Planta Medica 1998;64:711-3

[32] Burda C, Chen X, Narayanan R, El-Sayed MA. Chemistry and properties of nanocrystals of different shapes. Chem Rev 2005;105:1025-102.

[33] Veerapandian M, Lim SK, Nam HM, Kuppannan G, Yun KS. Glucosaminefunctionalized silver glyconanoparticles: characterization and antibacterial activity. Anal Bioanal Chem 2010;398:867-76.

[34] Jensen TR, Malinsky MD, Haynes CL, van Duyne RP. Nanosphere lithography: tunable localized surface plasmon resonance spectra of silver nanoparticles. J Phys Chem B 2000;104:10549-56.

[35] Sosa IO, Noguez C, Barrera RG. Optical properties of metal nanoparticles with arbitrary shapes. J Phys Chem B 2003;107:6269-75.

[36] Panacek A, Kvitek L, Prucek R, Kolar M, Vecerova R, Pizurova N, et al. Silver colloid nanoparticles: synthesis, characterization, and their antibacterial activity. J Phys Chem B 2006;110:16248-53.

[37] Hunter RJ.Zeta potential in colloid science: principles and applications. London: Academic Press; 1988

[38] Nidhin M, Indumathy R, Sreeram KJ, Balachandran UN. Synthesis of iron oxide nanoparticles of narrow size distribution on polysaccharide templates. Bull Mater Sci 2008;31:93-6.

[39] Ibrahim M, Alaam M, El-Haes H, Jalbout AF, de Leon A. Analysis of the structure and vibrational spectra of glucose and fructose. Ecl Quím Sao Paulo 2006;31:15-21.
[40] Nangia Y, Wangoo N, Goyal N, Shekhawat G, Suri CR. A novel bacterial isolate Stenotrophomonas maltophilia as living factory for synthesis of gold nanoparticles. Microb Cell Fact 2009;8:39, http://dx.doi.org/10.1186/1475-2859-8-39.

[41] Panigrahi S, Kundu S, Ghosh S, Nath S, Pal T. General method of synthesis for metal nanoparticles. J Nanopart Res 2004;6:411-4.

[42] Filippo E, Serra A, Buccolieri A, Manno D. Green synthesis of silver nanoparticles with sucrose and maltose: morphological and structural characterization. J Non-Crystalline Solids 2010;356:344-50.

[43] Minh DDL, Chang C, Trylska J, Tozzini V, McCammon JA. The influence of macromolecular crowding on HIV-1 protease internal dynamics. J Am Chem Soc 2006;128:6006-7.

[44] Otsuka H, Akiyama Y, Nagasaki Y, Kataoka K. Quantitative and reversible lectin-induced association of gold nanoparticles modified with $\alpha$-lactosyl- $\omega$ mercapto-poly (ethylene glycol). J Am Chem Soc 2001;123:8226-30.

[45] Zhang J, Geddes CD, Lakowicz JR. Complexation of polysaccharide and monosaccharide with thiolate boronic acid capped on silver nanoparticle. Anal Biochem 2004:332:253-60.

[46] Mehta SK, Chaudhary S, Gradzielski M. Time dependence of nucleation and growth of silver nanoparticles generated by sugar reduction in micellar media. Colloid Interface Sci 2010;343:447-53.

[47] Katti KK, Kattumuri V, Bhaskaran S, Katti KV, Kannan R. Facile and genera method for synthesis of sugar coated gold nanoparticles. Int J Green Nanotechnol Biomed 2009;1:B53-9.

[48] Castro L, Blazquez ML Gonzalez F, Munoz JA, Ballester A. Extracellular biosynthesis of gold nanoparticles using sugar beet pulp. Chem Eng J 2010;164:92-7.

[49] Islam MR. Household microwave-mediated carbohydrate-based production of silver nanomaterials. US Patent 8,062,407 (22-11-2011), to Northwest Missouri State University, Maryville, MO.

[50] Kim K-J, Sung WS, Suh BK, Moon S-K, Choi J-S, Kim JG, et al. Antifungal activity and mode of action of silver nanoparticles on Candida albicans. BioMetals 2009;22:235-42

[51] Kolar M, Urbanek K, Latal T. Antibiotic selective pressure and development of bacterial resistance. Int J Antimicrob Agents 2001;17:357-63.

[52] Chen S, Wu G, Zeng $\mathrm{H}$. Preparation of high antimicrobial activity thiourea chitosan- $\mathrm{Ag}^{+}$complex. Carbohydr Polym 2005;60:33-8.

[53] Sotiriou GA, Pratsinis SE. Antibacterial activity of nanosilver ions and particles. Environ Sci Technol 2010;44:5649-54.

[54] Park SJ, Jang YS. Preparation and characterization of activated carbon fiber supported with silver metal for antibacterial behavior. J Colloid Interface Sci 2003;261:238-43.

[55] Shanmugam S, Viswanathan B, Varadarajan TK. A novel single step chemica route for noble metal nanoparticles embedded organic-inorganic composite films. Mater Chem Phys 2006;95:51-5.

[56] Kumar CG, Mamidyala SK. Extracellular synthesis of silver nanoparticles using culture supernatant of Pseudomonas aeruginosa. Coll Surf B: Biointerfaces 2011:84:462-6. 